\title{
Identified Factors Behind Low Consumption of Animal Foods among the Children of 6 - 23 Months Old in Alive and Thrive Intervention Areas in Bangladesh
}

\author{
Umme Salma Mukta1, Barnali Chakraborty¹, Umme Sayka², Md. Raisul Haque², \\ Md. Moslem Uddin Mia ${ }^{4}$ \\ ${ }^{1}$ Research and Evaluation Division (RED), BRAC, Dhaka, Bangladesh \\ ${ }^{2}$ Campaign for Population Education (CAMPE), Dhaka, Bangladesh \\ ${ }^{3}$ Health Nutrition and Population Programme in BRAC, Dhaka, Bangladesh \\ ${ }^{4}$ Bangladesh Agricultural Research Council (BARC), Dhaka, Bangladesh \\ Email: salma.mukta@gmail.com, barnali.ch@brac.net, saykamoni@gmail.com, raisul.h@brac.net, \\ mia.mdmoslemuddin@gmail.com
}

Received 20 May 2015; accepted 5 June 2015; published 11 June 2015

Copyright (C) 2015 by authors and OALib.

This work is licensed under the Creative Commons Attribution International License (CC BY). http://creativecommons.org/licenses/by/4.0/

(c) (i) Open Access

\section{Abstract}

Background: In Bangladesh, more than two-thirds of total food consumption is rice as main staple, especially for the poor, in addition to some vegetables, pulses and small quantities of fish, meat, egg, etc. if and when available. The similar dietary pattern and practices were found for under two years old children in the intervention areas of Alive and Thrive ( $A$ \& $T$ ) project where consumption of animal foods by children was minimal even after being counseled on its rightly mentioned. Premising the facts, BRAC Research and Evaluation Division (RED) intended to investigate the factors that might have led to the consumption of least amount of protein from animal foods by the children in the $A \& T$ intervention areas. Objective: To investigate the dietary intake pattern of the children aged 6 - 23 months from beneficiary households and identify the factors that might have led to the lower intake of animal diets by those of the children. Methods: Mixed methods were applied to gather necessary information for the study. Quantitative tools were used to collect information on socioeconomic profile of the beneficiary households, feeding practice or dietary intake pattern of the children whereas qualitative tools were used to recognize the opportunities and barriers of the beneficiaries for feeding lower amount of animal foods to their children. Twelve upazilas were selected purposively from 4 districts (four geological corners of Bangladesh): Barguna, Sylhet, Chittagong and Dinajpur districts ( 3 from each). One control and two intervention upazilas were selected from each of the districts. The intervention areas were selected where $A$ $\& \mathrm{~T}$ supported health programmes and other BRAC health programmes were operating. The control areas were selected where other BRAC health programmes were operating except A \& T pro- 
gramme. The Pusti Kormi (PK), Shasthya Shebika (SS) and mothers/caregivers enrolled in the A \& T intervention areas were selected for interview, in addition to those who had involvement in services from the supervisory level. Results: Quantitative findings of the study revealed that food intake from animal sources in intervention areas was $7-12 \mathrm{~g}$ at the age 1 year and $18 \mathrm{~g}$ at 2 years where the recommended dietary average (RDA) was $14 \mathrm{~g}$ for less than one year and $16 \mathrm{~g}$ for less than 2 years. These were also lower in comparison to those counter parts of control areas. The qualitative findings indicated that the major factors hindered in feeding foods from animal sources were lack of knowledge, lack of awareness on protein deficiency, obstacles from the senior members of the family, myth like fish intake create worm, taboos, etc. Other barriers were found from the quantitative findings, like financial crisis (intervention area $80 \%$; control area $78 \%$ ), unavailability of the food products in local market (intervention area 5\%; control area $3 \%$ ), etc. Conclusion: Food consumption from animal sources might be increased among the under two years old children by reinforcing efforts in awareness development process addressing those of the challenges that might create demand for appropriate IYCF services at the household level.

\section{Keywords}

IYCF, Food Consumption, Animal Sources, Barriers, Factors, Bangladesh

Subject Areas: Anthropology, Biodiversity, Epidemiology, Food Science \& Technology, Global Health, Health Policy, Nursing, Nutrition, Pediatrics, Public Health

\section{Introduction}

The diet of most of the population in Bangladesh is mainly the cereals-based staples. About two-thirds of the total food consumption is rice along with vegetables, pulses and small amount of fish, if available [1]. The similar dietary pattern was found in the Alive and Thrive (A \& T) intervention areas where mothers were counseled on mentioned properly as a component of Infant and Young Child Feeding (IYCF). It was observed that most of the mothers/caregivers provided less diversified diet to their children even after being counseled by health volunteers. The internal monitoring team of A \& T programme of BRAC observed that the average consumption of foods particularly from animal sources was very low in the intervention areas. Animal foods are the major source of quality protein and essential micronutrients, namely, iron, zinc, etc. Fish, especially is one of the important animal food sources that supplies protein and micronutrients with high bioavailability [2] [3]. Children may become stunted if they do not receive adequate quantities of quality complementary foods after 6 months of age. It was estimated that around $6 \%$ of under five years old children's death can be prevented by ensuring optimal complementary feeding [4]. BRAC health care volunteers under Alive and Thrive program deliver messages and counsel the enrolled mothers to include food from animal sources along with vegetables fruits and other food groups in the daily menu of their children's diet. Despite rigorous messaging on the importance of diversified consumption for the children in A \& T intervention areas, low consumption of animal foods by them emphasizes the importance of exploring the facts behind it. There might be gaps in terms of knowledge, perception and practice of the mothers or the volunteers who had been delivering services in the intervention areas, or might be the other way around, for instance, the financial insufficiency of the households to buy animal foods, etc. BRAC-RED intended to identify the gaps that might hinder the animal food consumption of the children in different areas of A \& T, even after having intensive IYCF counseling.

\section{Objective}

This study aims to investigate into the dietary intake pattern of the children and identify the factors contributing to low consumption of animal foods by children aged $6-23$ months in A \& T intervention areas.

\subsection{Specific Objectives}

1) To determine the dietary intake pattern of the children aged 6 - 23 months through 24-hour dietary recall 
and three days dietary diversity information;

2) To identify the specific barriers prohibit the mothers to provide animal foods in the complementary food to their children;

3) To explore the knowledge and perception of the mothers/caregivers regarding the importance of providing animal foods in the complementary diet.

\subsection{Methods}

\subsubsection{Study Design}

Both quantitative and qualitative methods were employed to collect data.

\subsubsection{Study Population}

At the delivery level, SSs (Shyastha Sebikas) and PKs (Pushti Kormis) were selected as the respondents, who basically work as frontline health care providers to deliver the IYCF services under the A \& T programme. In addition, upazila managers (UM), branch managers (BM), and programme organizers (PO) were also interviewed to know their views. At the recipient level, mothers or caregivers and fathers of the children were selected as the respondents.

\subsection{Eligibility}

Inclusion criteria:

- Mothers having children aged 6 - 23 months;

- $\mathrm{SSs} / \mathrm{PKs} /$ other programme staff of BRAC working in the selected areas.

Exclusion criteria:

- Those who were visibly ill and/or uncomfortable to participate in the study;

- Mothers having no children aged 6 - 23 months.

\subsection{Study Site and Sample}

Twelve upazilas (Sub districts) from four districts (Dinajpur, Sylhet, Chittagong and Barguna) were selected using purposive sampling method from four different geographical locations. The intervention areas were selected where A \& T supported health programmes as well as others BRAC health programmes were operating. The control areas were selected where other BRAC health programmes were operating except A \& T programme. Study populations were selected randomly in such a way so that each district contains one control and two intervention upazilas.

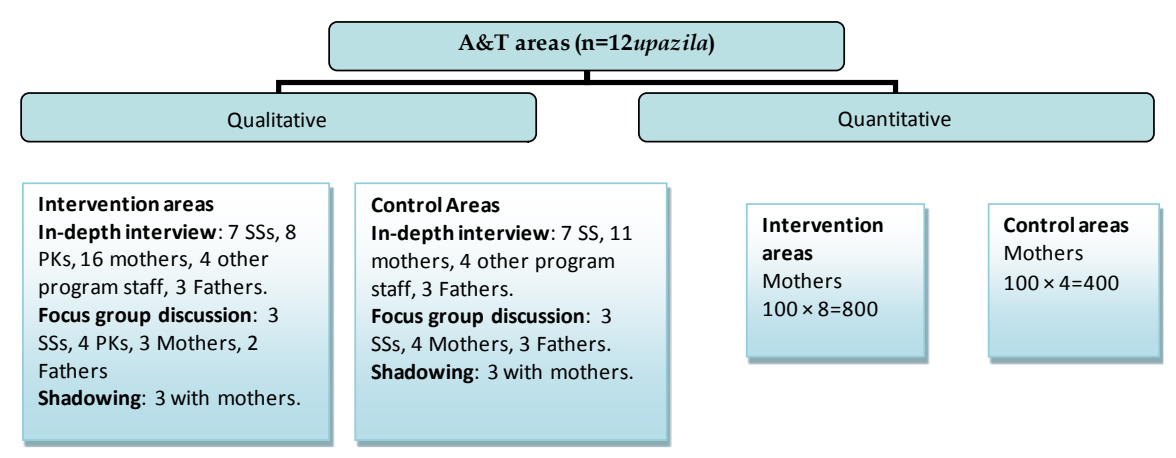

\subsection{Sample Size Selection Procedure}

The following formula was applied for sample size estimation.

$$
\begin{aligned}
\mathrm{n} & =\mathrm{Z}^{2} \mathrm{pq} / \mathrm{d}^{2} \\
& =(1.96)^{2}(0.5)(0.5) /(0.05)^{2} \\
& =384.16=384 \text { or approximately } 400,
\end{aligned}
$$

where

$$
\mathrm{n}=\text { required sample size; }
$$


$\mathrm{Z}=$ confidence limit set at 1.96 which corresponds to $95 \%$;

$\mathrm{p}=$ the estimated prevalence of relation between the maternal socioeconomic status and the outcome of the newborn;

$\mathrm{q}=1-\mathrm{p}=1-0.5=0.5$

$\mathrm{d}=$ degree of accuracy desired, usually set at $5 \%(0.05)$.

Multistage procedure for sample size selection was applied and the approximate sample made double to avoid precession error. So, the total sample would be $800(400 \times 2)$ for the eight intervention areas and half of it i.e., 400 from four areas were selected as control.

Simple random sampling was followed for entire stages to select mothers/caregivers, like

Selected upazilas $\rightarrow$ SSs $\rightarrow$ Mothers

Selected 12 upazilas $\rightarrow 10$ SSs (each upazila) $\rightarrow 10$ Mothers (each SS)

\subsection{Tools of the Study}

A pre-tested structured questionnaire was used to collect information on dietary intake, performance of SSs/PKs on complementary feeding, counseling, etc. Semi-structured questionnaires were used to conduct in-depth interview, shadowing, and focus group discussions (FGD) in exploring the knowledge and perceptions of the mothers and SSs. Thematic plan was used for qualitative data analysis by expert anthropologist.

In-depth interviews covered the following topics:

- Socioeconomic status of the key informants;

- Service delivery by SSs and PKs in their catchment HHs (other sources of information);

- Perception and practices on animal food consumption;

- Perceived barriers on animal food consumption and coping mechanisms;

- Unmet need to increase the animal consumption, if any.

The following themes were selected for conducting FGDs:

- Socioeconomic status of the respondents;

- Influencing factors of animal food consumption;

- Existing barriers to perform and practice, probable coping mechanism.

Shadowing with mothers covered the following topics:

- Practices of mothers on providing food to children from animal sources;

- By a daylong observation barriers from the family members tried to identified;

- Mothers knowledge, perception and practices.

\subsection{Data Collection}

Twenty-five enumerators were recruited to collect quantitative information. They were provided intensive training for 5 days to collect data of 24-hour dietary recall, 3-day dietary diversity, and other relevant information. Amount of household food consumption was measured by a set of standard measuring cups and spoon which were provided to the enumerators. Each enumerator collected data from four households every day. On the other hand, eight anthropologists were recruited to collect the qualitative data and conduct in-depth interviews, FGDs, and shadowing.

\subsection{Data Analysis}

The qualitative analysis was performed as per the thematic analysis plan. Quantitative data analysis was done using SPSS version 17. Household 24 hour dietary recall method was used to obtain the amount of food consumed by children, based on the dishes and ingredients. The ingredients were collected by details on the family or local amount, which were then converted into grams for convenience in determining the nutrient, especially the protein consumption. The household member responsible for preparing food and feeding children was interviewed to obtain information on food consumption over the past 24 hours. Besides, a 3-day recall method was followed to know the status of dietary diversity of the under-two children.

\subsection{Ethical Issues}

The respondents were informed and taken their consent prior to conduct the interviews and it was told that their 
names and other personal information was never be linked. And they had the freedom for disagree, stop, withdrawl the interview. Adequate care was also taken for maintaining confidentiality. All identifying information would be tailored in case studies cited in reports and only summatived data was circulated during focus groups discussion. All data were stored on password protected computer of the researcher. Only the primary investigators had access to this information. To guarantee ambiguity of the participants, codes was used to identify participants and groups in all stages of this research. Also a consent (either oral or written) from the participoent will be ensured to get the information from them. Ethical clearance for this study was approved from both the research and evaluation division (RED) and health, nutrition and population programme (HNPP) of BRAC. The areas and population of the study were BRAC HNPP areas where intervention provided under Alive and Thrive (A \& T) project. So by the demand of the programme to find out the barriers for appropriate infant feeding practices and cause of lower consumption of food from animal sources, the study was aimed to be conducted. For that necessary ethical clearance were taken from the HNPP programme and A \& T project as well from the RED also to conduct the study.

\section{Results}

\subsection{Socioeconomic Profile of the Respondents}

A total number of 1200 households were included in the study of which 800 were from intervention and the rest 400 from control areas. The results show that numbers of household members in all areas were 6207, of them 4129 were from intervention areas and 2078 were from control areas. Among them, $42 \%$ comprise the reproductive age group (20 - 45 years). The population distribution by age groups was almost similar irrespective of the intervention and control areas (see Table 1).

Table 1. Distribution of households by socioeconomic characteristics.

\begin{tabular}{|c|c|c|c|}
\hline \multirow[b]{2}{*}{ Study variables } & \multicolumn{3}{|c|}{ Study areas } \\
\hline & $\begin{array}{l}\text { Intervention } \\
\%(N=800)\end{array}$ & $\begin{array}{c}\text { Control } \\
\%(N=400)\end{array}$ & $\begin{array}{c}\text { All } \\
\%(N=1200)\end{array}$ \\
\hline \multicolumn{4}{|l|}{ Age in years } \\
\hline$<2$ & 19.9 & 19.9 & 19.9 \\
\hline $2-<5$ & 4.2 & 3.9 & 4.1 \\
\hline $5-9$ & 10.9 & 10.9 & 10.9 \\
\hline $10-19$ & 11.6 & 11.7 & 11.6 \\
\hline $20-45$ & 41.1 & 42.8 & 41.8 \\
\hline 46 and above & 12.1 & 10.7 & 11.7 \\
\hline Total & 4129 & 2078 & 6207 \\
\hline \multicolumn{4}{|l|}{ Have school education } \\
\hline No schooling & 24.3 & 27.5 & 25.3 \\
\hline Primary (I-V) & 40.6 & 38.6 & 40.0 \\
\hline Secondary and above & 35.1 & 33.9 & 34.7 \\
\hline Total & 2943 & 1464 & 4407 \\
\hline \multicolumn{4}{|l|}{ Religion } \\
\hline Muslim & 93.3 & 94.5 & 93.5 \\
\hline Non-Muslim & 7.0 & 5.5 & 6.5 \\
\hline Total & 800 & 400 & 1200 \\
\hline \multicolumn{4}{|l|}{ Occupation } \\
\hline Farming & 9.8 & 5.8 & 8.5 \\
\hline Business & 9.1 & 9.2 & 9.1 \\
\hline Services & 3.7 & 7.4 & 4.9 \\
\hline House wife & 37.0 & 35.1 & 36.4 \\
\hline Others & 40.3 & 42.5 & 41.1 \\
\hline Total & 3028 & 1506 & 4534 \\
\hline \multicolumn{4}{|l|}{ HH monthly income (Tk.) } \\
\hline$\leq 5000$ & 16.9 & 16.2 & 16.6 \\
\hline $5001-10,000$ & 50.2 & 54.4 & 51.6 \\
\hline $10,001-20,000$ & 26.3 & 21.4 & 24.7 \\
\hline $20,001+$ & 6.6 & 8.0 & 7.1 \\
\hline
\end{tabular}


It was found that $40 \%$ of the sampled population had primary education (I-V), about $35 \%$ secondary and higher level and the rest $25 \%$ had no schooling. Children below 7 years were excluded from the analysis for school education. The respondents were largely Muslim (95\%). Mostly the mothers were involved with the household chores rather than involving with any income generating activities (IGA) (put percentage here). Among the members of the selected $\mathrm{HH}$ were engaged in farming (about $9 \%$ ), business $(9 \%)$, service (5\%), and other IGAs (41\%) like daily wage laborer, begging, retired, tuitions, student, etc and the rest were housewives (36\%). Nearly half of the household members were involved with any IGA and about $52 \%$ had monthly income within the range of Tk. $5001-10,000$ (see Table 1).

\subsection{Complementary Feeding Practice of the Children by the Mothers/Caregivers}

Most of the mothers in intervention (93\%) and control (90\%) areas opined that the starting age of complementary feeding is after 6 months that is appropriate according to the WHO guidelines and recommendation (See Table 2). The rest $8 \%$ from both areas mentioned that the age of starting complementary feeding is before 6 months. Twenty four percent of the mothers both in intervention and control areas preferred cereals-based food

Table 2. Distribution of households by mothers' knowledge and practice with regards to complementary feeding (\%).

\begin{tabular}{|c|c|c|c|}
\hline & \multicolumn{3}{|c|}{ Programme areas } \\
\hline & Intervention (\%) & Control (\%) & All (\%) \\
\hline \multicolumn{4}{|c|}{ Complimentary food start } \\
\hline Before 6 month & 7.12 & 9.75 & 8 \\
\hline After 6 month & 92.88 & 90.25 & 92 \\
\hline \multicolumn{4}{|l|}{ Preference type of food for complimentary feeding } \\
\hline Cereals (rice/bread/suji) & 23.85 & 24.00 & 23.9 \\
\hline Fish & 15.45 & 14.4 & 15.1 \\
\hline Eggs & 14.4 & 13.8 & 14.2 \\
\hline Meat/liver & 8.55 & 6.9 & 8.0 \\
\hline Milk and milk product & 8.7 & 10.8 & 9.4 \\
\hline Vegetables & 21.75 & 21.3 & 21.6 \\
\hline Fruits & 7.65 & 7.2 & 7.5 \\
\hline Others & 0.3 & 0.3 & 0.3 \\
\hline \multicolumn{4}{|l|}{ Reasons for choose that type of food } \\
\hline Breast milk not sufficient & 83.55 & 87.6 & 84.9 \\
\hline For maintaining good health & 2.7 & 2.1 & 2.5 \\
\hline Cognitive development & 0.3 & 0.3 & 0.3 \\
\hline To met nutritional need & 3.6 & 2.1 & 3.1 \\
\hline Make the children familiar with complementary food & 1.5 & 2.1 & 1.7 \\
\hline Due to some other reasons & 9.15 & 4.2 & 7.5 \\
\hline \multicolumn{4}{|l|}{ Frequency of complimentary feeding } \\
\hline 3 times/day & 88.0 & 78.75 & 84.92 \\
\hline More than 3 times/day & 12.0 & 21.25 & 15.08 \\
\hline $\mathrm{N}$ & 800 & 400 & 1200 \\
\hline
\end{tabular}


like suji, rice, bread, etc, as the complementary foods for their children. Around $22 \%$ in both areas preferred vegetables followed by fish and egg $(15 \%)$.

Preference on meat, liver, milk and milk products, fruits, etc., was low in both areas $(<10 \%)$. Mothers in control areas preferred milk and milk products more (11\%) for their children in comparison to $9 \%$ of the intervention areas. According to the mothers' opinion reasons to prefer complementary foods were largely due to insufficient breast milk before 6 months of age from both interventions (84\%) and control areas (88\%). Very few mothers from intervention areas (4\%) mentioned about the additional nutrients requirement after 6 months of age. Other reasons were, maintaining good health, cognitive development, making the children familiar with semi solid foods, etc.

\subsection{Dietary Intake of the Children}

Information on children's food intake was collected from the mothers/caregivers through 24-hour dietary recall method. Table 3 indicates the average per capita per day food intake. It was found (see Table 3 ) that total average food intake was higher in intervention areas ( $258 \mathrm{~g} / \mathrm{capita} / \mathrm{day})$ compared to the counterpart in control areas ( $230 \mathrm{~g} / \mathrm{capita} / \mathrm{day})$. Among the foods, cereal consumption was higher about $60 \mathrm{~g}$. Average intake of milk and milk products was $57 \mathrm{~g}$ while it was higher $(65 \mathrm{~g})$ in the control areas compared to the intervention $(52 \mathrm{~g})$.

Intake of food from animal sources was not at satisfactory level in both intervention and control areas. Among the animal foods, it was found that only milk and milk product were consumed highest compared to others such as fish intake was $19 \mathrm{~g}$, meat $5 \mathrm{~g}$, and egg $13 \mathrm{~g}$ in intervention areas and fish intake $12 \mathrm{~g}$, meat $5 \mathrm{~g}$ and egg $8 \mathrm{~g}$ in

Table 3. Average food, energy and protein intake by children of 24-hour dietary recall.

\begin{tabular}{|c|c|c|c|}
\hline \multirow[b]{2}{*}{ Type of foods } & \multicolumn{3}{|c|}{ Amount of food intake g/capita/day } \\
\hline & $\begin{array}{c}\text { Intervention (mean) } \\
\mathbf{N}=\mathbf{8 0 0}\end{array}$ & $\begin{array}{l}\text { Control (mean) } \\
\quad \mathbf{N}=\mathbf{4 0 0}\end{array}$ & $\begin{array}{c}\text { All (mean) } \\
\mathbf{N}=1200\end{array}$ \\
\hline Cereal, rice & 62.0 & 53.48 & 59.17 \\
\hline Pulses & 6.85 & 4.12 & 5.94 \\
\hline Total vegetables & 42.61 & 30.90 & 38.70 \\
\hline Roots and tubers & 22.76 & 16.83 & 20.77 \\
\hline Leafy vegetables & 11.13 & 7.37 & 9.89 \\
\hline Non-leafy vegetables & 8.72 & 6.69 & 8.04 \\
\hline Animal sources & 89.25 & 89.64 & 89.43 \\
\hline Fish & 18.80 & 12.18 & 16.58 \\
\hline Meat/Liver & 5.16 & 4.67 & 4.99 \\
\hline Egg & 12.83 & 7.56 & 11.06 \\
\hline Milk \& milk product & 52.46 & 65.24 & 56.80 \\
\hline Fruits & 28.63 & 25.88 & 27.73 \\
\hline Oils/fats & 11.0 & 7.13 & 9.70 \\
\hline Other $^{*}$ & 18.02 & 18.70 & 18.23 \\
\hline Total & 258.35 & 229.85 & 248.66 \\
\hline Total energy (cal/capita/day) & 550.11 & 467.97 & 522.32 \\
\hline Plant sources & 452.65 & 382.14 & 428.72 \\
\hline Animal sources & 97.46 & 85.83 & 93.60 \\
\hline Total Protein (gm/capita/day) & 14.68 & 11.83 & 13.71 \\
\hline Plant sources & 7.45 & 6.13 & 6.99 \\
\hline Animal sources & 7.23 & 5.70 & 6.72 \\
\hline
\end{tabular}

${ }^{*}$ Others included soft drinks, some shop food, honey, sweet meat, sabu, etc. 
control areas. Intake of milk and milk products seemed to be higher, which might be due to inclusion of those foods where more or less milk was used as an ingredient, for example Payesh (sweet dish made by rice, sugar and milk), major ingredient was rice but it was recorded in this group.

Children's average energy intakes were 550 and $468 \mathrm{Cal} / \mathrm{capita} /$ day in intervention and control areas respectively (see Table 3), of which $>80 \%$ came from the plant sources. The energy came largely from cereals because most of the under-two children were fed suji (wheat product) with milk and khichuri (rice-pulse-vegetables mix preparation - hotchpotch), and the rest came from egg, milk and milk products, pulses, etc. Among the children protein intake was on average $14 \mathrm{~g} /$ capita/day (see Table 3). The amount between intervention and control areas was almost same. The child got around half of protein from the animal food sources.

\subsection{Mothers' Perception on Importance of Animal Food during Complementary Feeding Period}

We also tried to find out mothers' perception on animal food (see Table 4). More than two third (67\% from intervention areas) of the mothers responded that they felt to provide food to the children from animal sources, but the control areas mother didn't' felt so $(0.3 \%)$ while they started complementary feeding. Rest of the mothers did not feel like that. The mothers perceived the need to feed animal foods to keep their children well (29\%). The other reasons for providing animal foods as mentioned were for proper growth (23\% intervention and $21 \%$ control areas), to meet nutrient (21\%) requirements, for cognitive development (17\%), etc.

The findings reveal that the perception of the mothers from control areas was worst. Despite knowing usefulness of the animal foods/protein the mothers also mentioned some impairment of consuming those. About $49 \%$ mother in both areas pointed out that the children could not digest animal foods. Some mentioned that children could not chew these foods properly $(28 \%)$ and they did not like to eat. Some myths were identified that consumption of animal foods might be the cause of stomach problem, worm, etc., and a narrow difference existed between two groups.

\subsection{Barriers for Animal Food Consumption}

More than one-fourth $(27 \%)$ respondents told that they faced difficulties to feed their children from animal

Table 4. Distribution of households by mothers' perception on importance of animal food inclusion during complementary feeding (\%).

\begin{tabular}{|c|c|c|c|}
\hline \multirow[b]{2}{*}{ Characteristics } & \multicolumn{3}{|c|}{ Programme areas } \\
\hline & $\begin{array}{l}\text { Intervention } \\
\mathrm{N}=800\end{array}$ & $\begin{array}{l}\text { Control } \\
\mathrm{N}=400\end{array}$ & $\begin{array}{c}\text { All } \\
N=1200\end{array}$ \\
\hline \multicolumn{4}{|l|}{ Perceived in need to feed from animal source } \\
\hline $\begin{array}{l}\text { Yes } \\
\text { No }\end{array}$ & $\begin{array}{l}66.5 \\
33.0\end{array}$ & $\begin{array}{l}0.3 \\
0.2\end{array}$ & $\begin{array}{l}66.8 \\
33.2\end{array}$ \\
\hline \multicolumn{4}{|l|}{ Perceived usefulness of animal food } \\
\hline $\begin{array}{c}\text { For proper growth } \\
\text { Protect from disease }\end{array}$ & $\begin{array}{l}22.95 \\
10.65\end{array}$ & $\begin{array}{c}21.0 \\
7.5\end{array}$ & $\begin{array}{c}22.3 \\
9.6\end{array}$ \\
\hline $\begin{array}{c}\text { Keep children well } \\
\text { Cognitive development } \\
\text { To met nutrition need } \\
\text { Others }\end{array}$ & $\begin{array}{c}29.85 \\
18.75 \\
21.9 \\
0.45\end{array}$ & $\begin{array}{c}27.3 \\
14.7 \\
20.1 \\
0.3\end{array}$ & $\begin{array}{c}29.0 \\
17.4 \\
21.3 \\
0.4\end{array}$ \\
\hline \multicolumn{4}{|l|}{ Perceived impairment of animal food } \\
\hline Children can't digest & 52.2 & 42.0 & 48.8 \\
\hline Children can't chew it & 27.9 & 27.9 & 27.9 \\
\hline $\begin{array}{l}\text { Family members forbid } \\
\text { Myths (stomach problem, causes of worm, etc.) }\end{array}$ & $\begin{array}{c}10.5 \\
6.9\end{array}$ & $\begin{array}{c}6.9 \\
28.2\end{array}$ & $\begin{array}{c}9.3 \\
14.0\end{array}$ \\
\hline
\end{tabular}


sources (see Table 5). Most of them mentioned that the main barrier was financial, $83 \%$ from intervention and $78 \%$ from control areas. The other contributing factors mentioned by the respondents were lower supply of animal foods in nearby markets $11 \%$ in intervention areas and $6 \%$ in control areas, scarcity in households $(5 \%$ in intervention and $3 \%$ in control), family members specially in-laws and husbands prohibited the caregivers to feed foods from animal sources (3\% intervention areas, $2 \%$ control areas), and also sometimes obstacles came from neighbors and relatives.

Mothers tried to overcome those barriers by themselves, like arranging funds from other sources (46\%) and rearing cow, poultry, duck, etc. ( $26 \%$ both areas), about $13 \%$ mothers solved the financial constraints by discussing with their family members in both areas and some of them (12\% average both areas) minimized other expenses to increase expenditures for the children while the rest did not try anything.

\subsection{Essence from Qualitative Information}

A mother (Dinajpur control area) knew well about complementary feeding, though she started it before 6 months due to insufficient of breast milk. She tried to feed the child different fruits available in HH, egg, fish from own sources and tried to feed responsively. But she tried several times to feed the baby. This made the baby less appetite.

Findings from qualitative information analyses reveal that, in the intervention areas of Chittagong and Dinajpur, several mothers mostly add complementary foods to their children after the age of six months. Some mothers particularly from Sylhet informed that they would also start complementary feeding after ten months. In Sylhet, we found most of the Hindu families delayed to start providing complementary food due to their "Annoprashon"* ritual (Annaprashion is a ritual maintains by Hindu religion. Where child at first feed rice and other ingredients, after forming a prayer by their religious person called Brammon. That time a feast also arranged for guest. That time guest also brings some gift for the baby). In control areas may mothers reported of practicing early initiation of complementary feeding. A mother from Dinajpur said,

Table 5. Distribution of household members by perceived barriers of mothers faced to feed animal food (\%).

\begin{tabular}{|c|c|c|c|}
\hline \multirow[b]{2}{*}{ Characteristics } & \multicolumn{3}{|c|}{ Programme areas } \\
\hline & $\begin{array}{l}\text { Intervention } \\
\mathrm{N}=\mathbf{8 0 0}(\%)\end{array}$ & $\begin{array}{c}\text { Control } \\
\mathrm{N}=400(\%)\end{array}$ & $\begin{array}{c}\text { All } \\
N=1200(\%)\end{array}$ \\
\hline \multicolumn{4}{|l|}{ Is there any difficulties to feed animal food } \\
\hline $\begin{array}{l}\text { Yes, often } \\
\text { Not at all } \\
\text { Sometimes }\end{array}$ & $\begin{array}{c}23.4 \\
72.45 \\
4.35\end{array}$ & $\begin{array}{c}33.9 \\
61.5 \\
4.2\end{array}$ & $\begin{array}{c}26.9 \\
68.8 \\
4.3\end{array}$ \\
\hline \multicolumn{4}{|l|}{ Type of barriers } \\
\hline Financial & 82.6 & 78.0 & 80.3 \\
\hline From family members & 2.7 & 2.1 & 2.5 \\
\hline From relatives and neighbor & 2.0 & 0 & 2.0 \\
\hline Low supply in near market & 11.4 & 6.0 & 9.6 \\
\hline Animal sources not available & 5.4 & 3.3 & 4.7 \\
\hline Others & 1.05 & 0.6 & 0.9 \\
\hline \multicolumn{4}{|l|}{ Initiative taken to met the barriers } \\
\hline Started own cattle/goat/hen/duck etc raring & 25.8 & 25.8 & 25.8 \\
\hline Discuss with family to solve & 13.5 & 13.2 & 13.4 \\
\hline Lower other expenses to increase expenses for child & 10.8 & 13.8 & 11.8 \\
\hline Consult with A \& T staff/doctor & 2.7 & 0 & 1.8 \\
\hline Tried for another sources of income & 36.9 & 63.6 & 45.8 \\
\hline Nothing & 1.8 & 3.6 & 2.4 \\
\hline
\end{tabular}


"Before 6 months of age, we provided honey and cow's milk, if the child was crying. She provided her child a biscuit at morning, then rice with egg and some banana, in noon time rice with vegetables, in the afternoon serelac (infant formula), and breast milk only at night."

Through shadowing a mother in Sylhet control area, we found that she preferred to give breast milk to her child at the age of 10 months than providing complementary food. During whole day observation, we found that she fed mostly semai (vermicelli with milk) and breast milk while the child cried. And for once (at 11 a.m.) she tried for hotchpotch (made by rice, pulse, vegetables) to the child.

In the case of age-specific food, majority of the mothers in the intervention areas were enabled to mention about the quantity of food, because they knew from the A \& T programme and got a measuring bowl to feed their babies appropriately, but in control areas, mothers and even health workers couldn't mention it properly. The reasons of providing complementary food (CF) were mainly for cognitive development and get proper nutrition of the children of the considered age group in the intervention areas and reducing stunting in the control areas. For CF they mainly preferred rice, vegetables, egg and fish.

Shadowing in Dinajpur found that the mothers did not have any junk food for their children.

\subsection{Barriers Reported by the Respondents during Feeding}

An upazila manager form Barguna mentioned that the most common barriers to intake animal food were lack of money and education; myths, religious beliefs; and lack of motivation and knowledge. He suggested providing more manpower and creating opportunity to build a comprehensive IYCF practices. In his views the situation was worse in control areas.

\subsection{Financial}

In the intervention area of Sylhet, majority of mothers faced financial problem due to their husbands' ignorance. Their husbands either worked in London (UK) or engaged in business, and they preferred formula foods or other infant formula rather than providing animal foods in complementary feeding.

In Chittagong and Dinajpur, several mothers mentioned that due to limited income, they could not buy fish and meat regularly but they provided at least an egg per week while most of the PKs and SSs in intervention areas informed the similar problem. A SK from Dinajpur mentioned,

Mothers at least try to feed one boiled egg if her husband was unable to buy animal food. She observed that mothers would like to provide foods influenced by TV advertisement, but currently they were concerned and understood the importance of breast milk and providing animal foods in complementary foods and feeding to children after their counseling. In her catchment area, people had no financial constraint, but most of the mothers encountered problems with their family members, especially the elderly ones. In such situation, at first we counseled with the family members and tried to motivate in order to improve their awareness.

In the control areas majority of the mothers' notion was to provide animal foods despite of income limitations. They opined that income problem was temporary and its solution depended on one's husband's ability or willingness; if earning increased they could provide more animal food to their children.

\subsection{Social Barriers}

It was found that in Dinajpur intervention areas mothers and PKs encountered some superstitions imposed by their neighbors regarding feeding fish and meat to their children. They prohibited feeding food from animal sources to children, because they believed it would be harmful to the baby. The family members supported and influenced as well not to provide those foods to the baby.

\subsection{Domestic Barriers}

Majority of the mothers from both intervention and control areas stated that they faced problems from their elderly family members. They tried to practice the traditional way for their grand children and forbidden feeding foods from animal sources that might cause worm, stomach problem, etc. A mother from Dinajpur said,

Sometimes I could not provide fish to the child, though there was enough fish supply at home. Most of the time fish caused of dysentery, so I was rather not interested to give it to my child.

If the mothers fed animal foods ignoring their elderly family members' advice and the children had any health 
problem then the family members blamed them. So, they scared to follow the health workers' advice. A mother from Chittagong told,

They could not provide fish and meat even more food to the babies. If the baby became sick, then everybody would blame her.

\subsection{Some Allegory}

In Chittagong intervention area few mothers said that they could not provide egg which caused diarrhea. Also allegory existed on feeding liver. A mother said,

If they feed chicken liver then children's liver will be smaller and grow up as cowardice. On the other hand, as they belief that a baby cannot digest egg and similar food; these may be the causes of diarrhea.

Most of the PKs of Sylhet and Chittagong told that mothers believed that fish was harmful for children and caused worm. If they were fed more fish then the baby's belly would be enlarged. So, they could not provide animal food.

\subsection{Others Barriers}

In control areas, intake of animal food was found to be insufficient due to lack of knowledge. Most of the PKs from Sylhet and Chittagong stated that Hindu ritual Annoprashon was the most important to reduce intake of animal food as complementary due to most of the Hindu family could not break their rituals that delayed starting complementary foods. This might further delayed due to financial crisis, decision to perform the ritual by the household head or his absent from home, etc. As a result, late introduction of complementary food contributed in delaying in providing food from animal sources. In some cases, lack of mother's knowledge hindered intake of animal foods. Others were too busy with the HH chores that they did not get enough time to feed their babies. On the other hand, as they thought that due to providing animal food children defecated more, the mothers and family members got afraid and stopped feeding animal foods. Some mothers reported that due to providing animal foods like egg and meat to their children they faced some allergenic problems. In that case, they avoided all kinds of animal foods. Most of the health service providers mentioned that mothers complained that their children faced vomiting and worm problems after giving animal food.

The health service providers tried to counsel to mothers and also the family members that the problem encountered might not feeding animal foods, there might have some other reasons. Religious restriction was found in some areas where male POs were not allowed for supervision or counseling. On the other hand, in some areas fathers were idle/workless and even not thought about family planning; as a result they failed to provide enough animal food to their children. From shadowing, it was found that, the restrictions mostly came from husbands and relatives. In Barguna, husbands went for long period to work outside and returned home with lots of shop foods for their children and preferred to feed that. On the other hand, relatives also preferred to feed shop foods to their children while looking after them due to their mothers' HH chores. If any mother forbidden them, they did not care and sometimes might get angry. For that, most of the time, mothers didn't told anything. The mothers, who had their own sources of animal food, mostly preferred fish, egg in intervention areas and milk products in control areas. It was found in most the areas that mothers forgot to wash babies' and own hands with soap properly during feeding their children. As a result, the baby might have stomach problem or vomiting. The elderly and other family members including relatives suspected that it occurred due to feeding animal food. Then the mothers also believed them and frighten to feed the animal food again.

\section{Discussion}

During the period of complementary feeding, children more often develop under nutrition if not appropriately taken care of. According to the IYCF global strategy it also mentioned about safe complementary feeding practices after 6 months of age with adequate amount of energy, protein and micronutrients as appropriate for age [5] [6]. That is, the given foods need to be well diversified from all locally available foods groups. In the current study the findings overall suggested dietary intakes by the beneficiary children were though diversified but mainly with vegetables and other cereal based diets. Food consumption from animal sources was seemed to be lower in the age group 6 - 8 months compared to other age groups. Consumption of food by quantity was not at satisfactory level as well. This indicates that the diet might be of better quality, but the quantity was compro- 
mised. There was no significance observed between intervention and control areas.

Animal foods are the main sources of quality protein required to make its provision in complementary diet for the child. Among the respondents, the main animal food sources for the child were meat/liver, fish and egg. The ratio of these to meet protein requirement was $17 \%$, although protein's bioavailability from animal-based food is higher. But the contributions of other sources like fish, meat/liver, and egg were $5 \%, 6 \%$ and $4 \%$ respectively. The children consumed average $13 \%$ protein which came from animal sources $(7 \%)$ and rest came from plant sources. Because mostly the respondent preferred egg and milk/milk product for children and then liver, fish and meat for feed among both areas. These also help for practicing bio-availability of protein sources. Evidence suggests that during complementary feeding practices plant sources are insufficient to meet the needs of some essential nutrients [2] [5] [6]. Diets that are for the most part based on grains and legumes contain adequate amount of micronutrients which bioavailability particularly, iron and zinc are poor due to the presence of large amount of phytates [5] [7]. However, bioavailability of nutrients from animal sources is higher compared to that of plant sources due to its limiting amino acids [8]-[10]. Hence, it is recommended to daily menu of complementary food diets consist of meat, poultry, fish or eggs [5].

In general, the reasons behind the contributing factors for low consumption of animal food were lack of purchasing power, price hike of the food, lack of knowledge, barriers from family; like local myths and sometimes for some ritual. The study initiate that one of the obstacle was the myth and some ritual for the family to intake food from animal sourced especially for fish. Like mostly the myth was food from animal sources was not digestible by the children especially for the fish, along with though the child don't had teeth so he/she can't crush the food from animal sourced rather food from other sources like fruit, fiber, etc. A study showed that household daily income influences the food budget, particularly intake from animal sources due to costly [11] [12]. The barriers differed by regions. In Dinajpur, people had money and also had the ability to bought food from animal sources but they were less interested to provide food to the children from animal sources. And the reason behind that was while they started to feed from animal sources they found that the children suffered from dysentery and some other stomach problem, which frightening them to feed further food from animal sources. But in practical there was no scope for any kind of stomach problem due to food from animal sources.

We found unhygienic food preparation method or feeding or sanitation, etc may cause the problem. In Chittagong, the elderly members of the family preferred traditional IYCF practices, and also fathers were less likely to involve with income generating activities. The similar beliefs were found in Sylhet. On the other hand, in Sylhet due to more migrants, especially in London, people faced high price of commodity in local market. The poor people failed to buy beyond their limitation. Both intervention and control groups faced the problem of health service providers, especially POs supervising the PKs and SSs. The religious barriers restricted in allowing male POs to counsel the family. In control areas, consumption of milk and milk products - primarily cerealbased foods cooked with milk like vermicelli, suji, etc.- -were higher compared to other food groups. They mostly preferred shop foods like cerelac (formula baby food), which were readily available and easy to prepare. In some places in intervention areas, mothers were yet to be aware about the importance of animal foods and disadvantages of processed foods. In addition, motivational activities need to be strengthened in favor of providing animal foods as complementary to the children instead of shop/processed foods that might cause of appetite loss or sickness. The situation is better compared in intervention areas. Where we found that the consumption of milk or milk product was lower but the other sources of animal food like egg, fish, meat and liver was higher in the intervention areas compared to control areas. That means the intervention packages for appropriate infant and young child feeding practices was success in the programme areas where the special emphasis on feeding from animal sources was also pretty much succeed.

\section{Limitations}

Fathers' in-depth and FGDs could not be conducted in Barguna district due to their unavailability. During visit, they went to the sea for fishing for their livelihood.

\section{Conclusion and Recommendation}

\subsection{Conclusion}

In conclusion, it could be said that dietary diversification in the study areas was found to be noticeable in terms 
of quality, but quantity was inadequate, hindering nutrient adequacy, specially protein and micronutrients from animal sources. Traditional practices, myth and taboos, prohibition of elderly family members, fathers, etc. still remained as barriers in providing animal foods to children as weaning and supplementary food. Efforts should be strengthened in awareness development process in creating demand for IYCF services at household level to improve children's nutritional status.

\subsection{Recommendations}

1) Special attention should be given in providing food from animal sources to children aged 6 - 8 months and should be continued until customized to family foods;

2) Traditional practices, myth and taboos, misconception and prohibition of elderly family members, fathers, etc. still remained as barriers in providing animal foods to children at weaning and supplementary stages. Initiatives need to be taken to minimize these barriers by more counseling and forum, meeting with the family members.

\section{Conflicts of Interest}

The authors declare that they have no conflicts of interest.

\section{Contributions}

All authors were equally involved in the conceptualization and design of the study. USM

Lead data collection, analysis and interpretation with substantive inputs from BC, US, RH and MUM. The paper developed with substantive input from BC and MUM.

\section{Acknowledgements}

The authors gratefully acknowledge the continued support and guidance of Dr. Kaosar Afsana, Director, Health Nutrition and Population Programme (HNPP) and Professor WMH Jaim, Director, Research and Evaluation Division of BRAC. Special thanks are deserved by the staff and local implementing partners of Alive \& Thrive (A $\&$ T) project in Barguna, Dinajpur, Sylhet and Chittagong districts. The authors heartily appreciate the assistance provided by the RED colleagues and BRAC-HNPP-A \& T team and the administrative officer in supporting field. Appreciation is greatly deserved by the research assistants who participated in data collection and transcribing of qualitative data. The authors sincerely thank the data management team, especially ANM Mahfuzur Rahman and Md. Jasim Uddin, for their rigorous support in data handling, coding, cleaning, etc. Finally, the authors thank all the respondents who actively participated in the interviews and expressed their views. Funding was provided by Building Resources Across Communities (BRAC), and Alive and Thrive project under Health Nutrition and population Programme of BRAC.

\section{References}

[1] Jahan, K. and Hossain, M. (1998) Nature and Extent of Malnutrition in Bangladesh, Bangladesh National Nutrition Survey, 1995-1998. Institute of Nutrition and Food Science, Dhaka University, Dhaka.

[2] WHO (1974) Handbook on Human Nutritional Requirements. WHO Monograph Series No. 61, World Health Organization, Geneva, 23-28.

[3] Heinbuch, U. (1994) Animal Protein Sources for Rural and Urban Populations in Ghana. Programme for the Integrated Development of Artisanal Fisheriesin West Africa, Cotonou, 25 p. + annex, IDAF/WP/58.

[4] Ahmed, T., Roy, S.K., Alam, N., Ahmed, A.M.S.S., Ara, G., Bhuiya, A.U., et al. (2005) Baseline Survey 2004 of National Nutrition Programme: Report. International Centre for Diarrhoeal Disease Research, Dhaka, 319 p. (ICDDR, B Special Publication No. 124)

[5] World Health Organization. (2003) Global Strategy for Infant and Young Child Feeding. World Health Organization and UNICEF, Geneva, Switzerland, ISBN 9241562218.

http://whqlibdoc.who.int/publications/2003/9241562218.pdf. Retrieved 2009-09-20

[6] WHO (2009) World Health Report on Infant and Young Child Feeding Guideline.

[7] Dewey, K. (2013) The Challenge of Meeting Nutrient Needs of Infants and Young Children during the Period of Com- 
plementary Feeding: An Evolutionary Perspective. The Journal of Nutrition, 143, 2050-2054. http://dx.doi.org/10.3945/jn.113.182527

[8] Food and Agriculture Organization/World Health Organization (1990) Protein Quality Evaluation; Report of the Joint FAO/WHO Expert Consultation. FAO Food and Nutrition Paper, Vol. 52, Rome, Italy.

[9] Food and Nutrition Board, Institute of Medicine (2004) Dietary Reference Intakes for Water, Potassium, Sodium, Chloride, and Sulfate. National Academy Press, Washington DC.

[10] Hellen Keller International (HKI) \& World Food Programme (WFP) (1988) Tables of Nutrient Composition of Bangladeshi Foods. Published by Hellen Keller International, Bangladesh; Printed by Moni printers \& Packages Ltd., Dhaka.

[11] Davis, C.G. (2002) Linkage between Socio-Economic Characteristics, Food Expenditure Patterns and Nutritional Status of Low-Income Households: A Critical Review. American Journal of Agricultural Economics, 64.

[12] Lemon, P.W.R. (1995) Do Athletes Need More Dietary Protein and Amino Acids? International Journal of Sports Nutrition, 5, S39-S61.

\section{Acronyms}

AED: Academy for Educational Development

AM: Area Manager

A \& T: Alive \& Thrive

BF: Breastfeeding

BM: Branch Manager

CF: Complementary Feeding

BHNPP: BRAC Health Nutrition and Population Programme

EBF: Exclusive Breastfeeding

FGD: Focus Group Discussion

HH: Household

IYCF: Infant and Young Child Feeding

PO: Program Organizer

PK: Pusti Kormi

RED: Research and Evaluation Division

SS: Shasthya Shebika

SK: Shasthya Kormi

UZ: Upazila 